DOI: 10.12957/demetra.2017.26701

\title{
A aquisição de alimentos da agricultura familiar pelo PNAE no município de Alegre-ES
}

\section{Purchasing food produced by family farmers through PNAE in the municipality of Alegre, Espírito Santo State, Brazil}

\author{
Rafael Rodrigues \\ Haloysio Mechelli de Siqueira ${ }^{2}$ \\ Caio César Soares Biancardi ${ }^{3}$ \\ Magda Aparecida Nogueira Andrade ${ }^{4}$ \\ Lucas Motte Valente ${ }^{5}$ \\ Lorenza Bandeira de Paula ${ }^{5}$ \\ ' Escola Família Agrícola de Marilândia. \\ Marilândia-ES, Brasil. \\ ${ }^{2}$ Universidade Federal do Espírito Santo, \\ Departamento de Medicina Veterinária, Centro \\ de Ciências Agrárias e Engenharias. Alegre-ES, \\ Brasil. \\ ${ }^{3}$ Engenheiro Agrônomo autônomo. Iconha-ES, \\ Brasil. \\ ${ }^{4}$ Universidade Federal do Espírito Santo, \\ Departamento de Zootecnia, Centro de Ciências \\ Agrárias e Engenharias. Alegre-ES, Brasil. \\ ${ }^{5}$ Universidade Federal do Espírito Santo, Centro \\ de Ciências Agrárias e Engenharias. Alegre-ES, \\ Brasil \\ Correspondência / Correspondence \\ Haloysio Mechelli de Siqueira \\ E-mail:haloysio.siqueira@ufes.br
}

\section{Resumo}

Este artigo aborda o Programa Nacional de Alimentação Escolar (PNAE) no município de Alegre-ES, com o objetivo de caracterizar o processo de compra de alimentos da agricultura familiar para atender a esse mercado, enfocando a evolução desse processo no período de 2013 a 2015. As fontes de dados utilizadas foram as seguintes: os editais das Chamadas Públicas e seus respectivos relatórios, disponíveis no site da prefeitura de Alegre; os projetos de venda das associações rurais disponibilizados pelo Sindicato dos Trabalhadores Rurais; e documentos do FNDE, disponíveis em seu site. Verificou-se que o porcentual mínimo de compra obrigatória não foi cumprido no ano de 2013, ficando em 15,52\%, mas chegou a 116,68\% do repasse do FNDE, em 2014. O número de agricultores de Alegre participantes do programa cresceu 2,8 vezes, de 2013 para 2015, chegando a 39 agricultores. Quanto à diversidade de alimentos, houve um aumento da ordem de $54 \%$, passando de 22, em 2013, para 34 diferentes alimentos adquiridos em 2015. Concluiu-se que o PNAE de Alegre, mesmo diante dos desafios colocados, cumpre o seu papel de interligar a agricultura familiar à alimentação escolar, ajudando a promover o desenvolvimento rural sustentável e, ao mesmo tempo, trazendo segurança alimentar e nutricional às crianças e adolescentes que estudam nas escolas municipais.

Palavras-chave: Alimentação Escolar. Agricultura. Comércio. Segurança Alimentar e Nutricional. 


\section{Abstract}

This paper discusses the National School Feeding Program (PNAE) in the municipality of Alegre, Espírito Santo State, Brazil, in order to characterize the process of buying food from family farmers to serve this market, focusing on the evolution of this process from 2013 to 2015 . The sources of the data used were as follows: Public Notices and the respective reports, available on the website of The City Council of Alegre; sales projects of rural associations provided by the Rural Workers' Union; and FNDE (National Education Development Fund) documents available on their website. It was found that the compulsory minimum purchase percentage was not met in 2013 (it was 15.52\%), but it amounted to $116.68 \%$ of FNDE's fund transfer in 2014. The number of farmers of Alegre participating of PNAE grew 2.8 times, from 2013 to 2015, reaching 39 farmers. There was a $54 \%$ increase in food diversity, from 22 in 2013 to 34 different foods purchased in 2015. It was concluded that the PNAE of Alegre, even in the face of the challenges posed, is fulfilling its role to link family agriculture with school feeding, helping to promote sustainable rural development while bringing food and nutritional security to children and adolescents who study in public schools.

Keywords: School Feeding. Agriculture. Marketing, Food and Nutrition Security.

\section{Introdução}

O Programa Nacional de Alimentação Escolar (PNAE) foi criado em 1955, com a denominação de "Campanha de Merenda Escolar". De 1955 até 1993, o PNAE foi um programa centralizado e todo o cardápio e aquisição de gêneros alimentícios era feito pelo Ministério da Educação, via processo licitatório. Somente a partir de 1994, com a Lei no 8.913, passou a ocorrer a descentralização dos recursos, com repasses às secretarias estaduais e municipais de Educação para assumirem todo o processo. ${ }^{1}$

Em 2009, o PNAE passou por outra grande mudança. A Lei Federal no 11.947 estabeleceu que no mínimo 30\% dos recursos financeiros repassados pelo Fundo Nacional de Desenvolvimento da Educação (FNDE), para custear a alimentação escolar, às secretarias municipais ou estaduais 
de Educação, devem ser destinados à aquisição de alimentos oriundos da "agricultura familiar ou dos empreendimentos familiares rurais”. ${ }^{2}$

Assim, de acordo com as novas diretrizes definidas em 2009, o encontro entre a alimentação escolar e a agricultura familiar pode promover uma importante transformação na realidade social brasileira, ao permitir que alimentos diversificados, sazonais, com vínculo regional e até mesmo orgânicos, produzidos por agricultores familiares, possam ser consumidos diariamente pelos alunos da rede pública de educação de todo o Brasil, compreendendo um cardápio variado que respeite a cultura regional e os hábitos alimentares saudáveis. ${ }^{2}$

O PNAE se reveste de grande importância porque permite conciliar a necessidade de garantir a segurança alimentar e nutricional às crianças e adolescentes em idade escolar com a criação de um novo canal de comercialização para a agricultura familiar, em nível local, gerando trabalho e renda no campo e ajudando a dinamizar a economia local.-5 Programas com efeitos semelhantes também existem em outros países, como Escócia e Itália, os quais foram estudados por Sonnino et al. ${ }^{6}$

Esse novo canal de comercialização corresponde a uma das formas de acesso dos agricultores familiares aos mercados, descritas por Wilkinson,? quais sejam: o acesso direto (sobressaindo o mercado local/informal), o acesso via atravessador, a integração com as agroindústrias e o acesso por meio das compras do poder público, que é o caso do PNAE. Também se distinguem o mercado de commodities, onde as relações são impessoais e mediadas apenas pelo preço, e os "novos mercados", caracterizados por diferentes processos de fidelização com base na identidade específica dos produtos e processos produtivos. Tais novos mercados englobam as especialidades de nichos, os orgânicos, os artesanais, os solidários e os institucionais. ${ }^{7}$

Em 2010, primeiro ano de obrigatoriedade das aquisições da agricultura familiar pelo PNAE, 47,4\% dos municípios brasileiros fizeram esse tipo de aquisição, sendo que o porcentual de compra foi, em média, de 22,7\% do repasse/FNDE, abaixo do mínimo exigido (30\%) pela Lei de 2009. Há um destaque para a região sul do país, que apresentou o maior porcentual (71,3\%) de municípios adquirindo, frente à região centro-oeste, que teve apenas $35,3 \%{ }^{8}$

No Estado do Espírito Santo, as aquisições da agricultura familiar foram iniciadas em 2010. Entre os trabalhos já realizados sobre esse tema, no Espírito Santo, enquadram-se o de Alves, ${ }^{9}$ que discute o PNAE como intervenção para recriar a agricultura camponesa capixaba, e o de Aoki et al., ${ }^{10}$ referente à inserção dos agricultores familiares do município de Pedro Canário no PNAE.

a A Lei Federal no 11.326/2006 considera "agricultor familiar ou empreendedor familiar rural" aquele que pratica atividades econômicas no meio rural e possui área não superior a quatro módulos fiscais, empregando mão de obra, predominantemente, da própria família e dirigindo o seu estabelecimento ou empreendimento com sua família. Além disso, deve ter um percentual mínimo da renda familiar originada de atividades econômicas do seu estabelecimento ou empreendimento, na forma definida pelo Poder Executivo, conforme a Lei no $12.512 / 2011$. 
No ano de 2014, o FNDE repassou às secretarias municipais e à Secretaria Estadual de Educação do Espírito Santo um total de R\$ 61.388.808,40, ${ }^{\text {b }}$ para custear a alimentação escolar pública. Considerando que os governos chegaram a aplicar, pelo menos, o mínimo exigido por lei nas aquisições da agricultura familiar, obtém-se um total de $\mathrm{R} \$ 18.416 .642,00$, que estaria ajudando a dinamizar a economia rural capixaba.

Por outro lado, o Censo Agropecuário de 2006 revelou que, nesse estado, os estabelecimentos familiares representavam $80 \%$ do total, mas de cada dez pessoas que trabalhavam no campo seis estavam na agricultura familiar. ${ }^{11}$ Isso demonstra a relevância social da agricultura familiar no contexto estadual, o que justifica a execução de programas governamentais como o PNAE, que podem contribuir para reforçar essa categoria socioeconômica, conforme também já foi defendido em outros estudos. ${ }^{3,12,13}$

No município de Alegre, situado no Estado do Espírito Santo, a aquisição de alimentos da agricultura familiar pelo PNAE vem sendo feita desde 2010. Mas, foi a partir de 2014 que esse processo cresceu em diversidade e quantidade de alimentos, além de ter ampliado a inserção de agricultores familiares nesse mercado institucional, ${ }^{14}$ cuja magnitude ainda não havia sido estudada.

Por isso, o presente artigo procura caracterizar a inserção da agricultura familiar na alimentação escolar no município de Alegre-ES, no período de 2013 a 2015, descrevendo o comportamento da demanda e da oferta de alimentos da agricultura familiar, o número de agricultores e associações participantes, bem como o processo de gestão do PNAE no tocante às compras da agricultura familiar. Espera-se, com isso, contribuir para dar maior visibilidade da importância desse programa governamental para a agricultura familiar, a comunidade escolar e a sociedade como um todo.

\section{Metodologia}

O presente trabalho se configura como uma pesquisa documental descritiva. Foi desenvolvido no município de Alegre, localizado no sudoeste do Estado do Espírito Santo e no Território do Caparaó,

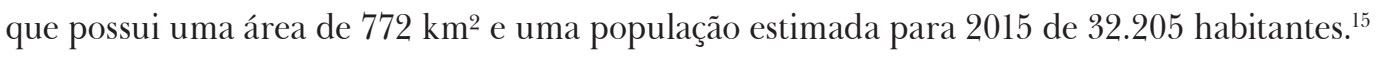

A rede municipal de ensino atendida pelo PNAE era composta, em 2015, por 30 escolas com um total de 2.297 estudantes matriculados. ${ }^{16} \mathrm{E}$ os estabelecimentos agropecuários familiares, de acordo com o Censo Agropecuário de 2006, representavam 79,3\% do total, ocupando 42,6\% da área agrícola. ${ }^{11}$

b Dados do FNDE (disponíveis em: http://www.fnde.gov.br/programas/alimentacao-escolar/alimentacaoescolar-consultas/repasses-financeiros). Como não constavam os municípios Fundão e Dores do Rio Preto, acrescentou-se os dados obtidos diretamente junto às respectivas prefeituras. 
Para caracterizar a inserção da agricultura familiar no PNAE, foram elaboradas duas planilhas utilizando o programa Microsoft Excel. A primeira, referente aos dados das Chamadas Públicas para aquisição de alimentos da agricultura familiar, que revela a demanda no mercado do PNAE; e a segunda, referente aos projetos de venda apresentados pelos agricultores familiares, que revela a oferta de alimentos nesse mercado. Considerou-se os anos de 2013, 2014 e 2015.

Nessas planilhas, foram descritas a variedade de alimentos, a quantidade de agricultores familiares participantes e os valores finais das Chamadas e dos projetos apresentados.

As fontes de dados do PNAE municipal utilizadas foram as seguintes: as Chamadas Públicas e seus respectivos relatórios, disponíveis no site da prefeitura de Alegre; os projetos de venda das associações rurais disponibilizados pelo Sindicato dos Trabalhadores Rurais de Alegre; e documentos do FNDE, disponíveis em seu site.

\section{Resultados e Discussão}

\section{A construção das Chamadas Públicas e dos projetos de venda de alimentos pelo PNAE no município de Alegre-ES}

A Entidade Executora do PNAE em Alegre-ES é a Secretaria Municipal de Educação, que recebe recursos diretamente do FNDE para a aquisição de alimentos.

Nesse município, vem ocorrendo o processo de "gestão compartilhada" do PNAE, envolvendo essa secretaria, as associações dos agricultores familiares e o Sindicato dos Trabalhadores Rurais, de modo a manter um diálogo permanente visando à construção participativa das Chamadas Públicas e dos projetos de venda de alimentos. Esse processo envolve ações como a negociação da variedade, da quantidade e dos preços dos alimentos que serão adquiridos pelo município, aliadas a um planejamento em conjunto da produção, com as associações rurais interessadas, para atender melhor à demanda das escolas. Inclusive, há um projeto de extensãoc que apoia e assessora esse processo.

O PNAE pode ser entendido como um mercado público e institucional que foi "construído socialmente”. Segundo Panzutti, ${ }^{17}$ essa abordagem pressupõe que o mercado não é uma entidade separada dos agentes econômicos, como uma "mão invisível” determinante do seu funcionamento. Na verdade, o mercado é "[...] resultado das estruturas e interações sociais, dentro de um contexto

c Projeto intitulado "Promovendo a comercialização solidária dos agricultores familiares de Alegre-ES". É coordenado pela Universidade Federal do Espírito Santo (UFES) e executado em parceria com o Sindicato dos Trabalhadores Rurais, a Rede da Agricultura Familiar e o Instituto Capixaba de Pesquisa, Assistência Técnica e Extensão Rural (INCAPER). 
histórico determinado [...], que se organiza de acordo com o autointeresse dos agentes inseridos em situações específicas [...]".17

No caso dos mercados de compra e venda direta, ou seja, sem a atuação de intermediários entre os produtores e os consumidores, a proximidade social, o interconhecimento e a confiança mútua se colocam como condições básicas do processo de construção dos mesmos. E os mercados públicos requerem mecanismos de governança abertos e democráticos, por lidarem com fundos públicos para atender a demandas específicas. ${ }^{18}$

A referida experiência de gestão compartilhada, realizada em Alegre, demonstra que essa construção social realmente é possível, ampliando e qualificando o mercado voltado à alimentação escolar, a partir da organização social dos agricultores familiares. Eles passaram a exercer ações coletivas para sensibilizar, reivindicar e cobrar do poder público municipal, de uma forma bem mais articulada, a abertura de canais de diálogo quanto às questões pertinentes ao PNAE, em especial na elaboração participativa das Chamadas Públicas.

No que se refere à gestão do PNAE, especificamente quanto à forma de construção das Chamadas Públicas, foram identificados poucos estudos a respeito. Malina ${ }^{19}$ relata que, por meio do Projeto Nutre SP, ${ }^{d}$ foram realizadas oficinas nas regiões paulistas de Bragança Paulista e Mogi Mirim, Sorocaba, Sudoeste Paulista e Vale do Ribeira, no ano de 2011, voltadas para organizações da agricultura familiar. Nessas oficinas discutiu-se as dificuldades e possibilidades de solução para implementar a Lei no 11.947/2009, mas a questão da falta de diálogo entre as partes envolvidas (prefeituras e organizações da agricultura familiar) foi uma das que apareceram em todas as oficinas.

Malina ${ }^{19}$ recomenda a aproximação da prefeitura com os agricultores locais, previamente ao lançamento da chamada pública, para que "consigam se adaptar melhor às condições de cada uma das partes para implementar o aparato jurídico necessário”.

Por sua vez, Aroucha, ${ }^{20}$ em pesquisa realizada junto ao Projeto Nutre Nordeste, ${ }^{\mathrm{e}}$ em nove estados do nordeste brasileiro, enfocando os dois primeiros anos (2010 e 2011) de implementação da Lei no 11.947/2009, verificou que na elaboração e publicação das Chamadas Públicas algumas secretarias de Educação (municipais e estaduais) criaram dificuldades para que as Chamadas pudessem ser atendidas pelas organizações da agricultura familiar, como: adoção de diferentes modalidades de Chamadas; pouca publicitação das mesmas em locais e meios mais acessíveis às

d Projeto executado pelo Instituto Via Pública, em parceria com a Secretaria de Agricultura Familiar do extinto Ministério do Desenvolvimento Agrário, visando fomentar a articulação entre a agricultura familiar e as prefeituras paulistas para implementar a Lei no 11.947/2009.

e Projeto executado pela ONG AGENDHA, contando com a mesma parceria e tendo objetivo semelhante ao do Projeto Nutre SP, antes referido, com atuação nas nove capitais e seis municípios metropolitanos da região Nordeste. 
referidas organizações; não inclusão de alimentos tradicionalmente produzidos pela agricultura familiar; e até mesmo limitar-se à realização de sistema de compra por pregão.

Analisando a atuação dos gestores públicos, nas aquisições da agricultura familiar pelo PNAE, Belik $^{21}$ afirma que, de modo geral, os gestores

são refratários às mudanças e não encaram com boa vontade a pulverização dos procedimentos decorrente da incorporação da agricultura familiar, o que evidentemente gera mais trabalho e mais demandas por parte de um setor que até então estava excluído da administração.

Essa postura inoperante dos gestores públicos se torna, então, um grande obstáculo à efetivação do processo de construção participativa das Chamadas Públicas nos estados e municípios, tal como ocorre no caso de Alegre-ES.

Os passos descritos a seguir devem ser obedecidos para a construção da Chamada Pública e dos projetos de venda de alimentos pelo PNAE. Cabe frisar que a Chamada representa a demanda das escolas municipais e que nem sempre toda essa demanda é atendida pelos projetos de venda dos agricultores familiares, os quais representam a oferta de alimentos.

\section{Orçamento}

A Secretaria Municipal de Educação deve identificar o valor do repasse do FNDE, o qual é feito com base no Censo escolar do ano anterior. Por exemplo, em Alegre, no ano 2014, foi no valor de $\mathrm{R} \$ 333.840,00$. Conforme previsto na Resolução FNDE no 26/2013, ${ }^{22}$ o porcentual mínimo (30\%) de compra da agricultura familiar poderá ser dispensado apenas quando presente uma das seguintes circunstâncias, desde que devidamente comprovadas pela Entidade Executora na prestação de contas:

I - a impossibilidade de emissão do documento fiscal correspondente;

II - a inviabilidade de fornecimento regular e constante dos gêneros alimentícios, desde que respeitada a sazonalidade dos produtos; e

III - as condições higiênico-sanitárias inadequadas.

O valor repassado pelo FNDE a estados e municípios, por dia letivo e para cada aluno, é definido de acordo com a etapa e modalidade de ensino. ${ }^{\mathrm{f}}$

f Valores atuais: Creches: R \$ 1,00; Pré-escola: R \$ 0,50; Escolas indígenas e quilombolas: R \$ 0,60; Ensino fundamental, médio e educação de jovens e adultos: $\mathrm{R}$ \$ 0,30; Ensino integral: $\mathrm{R} \$ 1,00$; Alunos do Programa Mais Educação: R \$ 0,90; e Alunos que frequentam o Atendimento Educacional Especializado no contraturno: R \$ 0,50 (Disponível em: http://www.fnde.gov.br/programas/alimentacao-escolar/alimentacaoescolar-apresentacao. Acesso em: 07 mar. 2016). 


\section{Cardápio}

De posse do levantamento feito anteriormente dos produtos da agricultura familiar local, o nutricionista deve elaborar os cardápios da alimentação escolar, incluindo alimentos regionais, com respeito às referências nutricionais e aos hábitos alimentares locais, e conforme a safra. Chaves et al. ${ }^{23}$ salientam a importância do nutricionista na elaboração do cardápio escolar, cabendo ao mesmo planejar, elaborar, acompanhar e avaliar o cardápio da alimentação escolar.

\section{Pesquisa de preço}

No município de Alegre-ES, a pesquisa de preços dos alimentos tem sido feita por meio do referido projeto de extensão. São realizadas três cotações anuais, nos meses de março, agosto e novembro, em três supermercados locais e na feira municipal, fazendo a média dos preços praticados nesses mercados. A iniciativa de realizar as cotações também ao longo do ano é uma forma de levar em conta as possíveis flutuações de preços dos alimentos.

Mas a Resolução FNDE no 26/2013, ${ }^{22}$ em seu artigo 29, exige apenas que o preço de aquisição seja "o preço médio pesquisado por, no mínimo, três mercados em âmbito local, territorial, estadual ou nacional, nessa ordem, priorizando a feira do produtor da agricultura familiar, quando houver".

A equipe desse projeto também tem realizado, em conjunto com os agricultores, o levantamento dos custos de produção e comercialização, como base para definição dos preços justos dos alimentos. Se os produtores considerarem que os valores médios de mercado apurados não estão cobrindo seus custos, procuram a Secretaria de Educação a fim de discutirem os preços a serem pagos.

\section{Chamada Pública}

A aquisição de alimentos da agricultura familiar para a alimentação escolar pode ser realizada dispensando-se o processo licitatório, nos termos do art. 14 da Lei no $11.947 / 2009,{ }^{2}$ desde que atendidas as condições lá definidas.

A Chamada Pública é

um processo simplificado utilizado para aquisição de gêneros da agricultura familiar com recursos federais repassados pelo FNDE às Entidades Executoras (prefeituras e secretarias estaduais/distrital de Educação) para atender à demanda da alimentação escolar. Não utiliza o preço como critério de seleção dos projetos de venda, considerando a lógica de produção da agricultura familiar (menor escala de produção, dificuldade de logística e distribuição e outros), porém os preços praticados devem ser compatíveis com os preços de mercados locais. ${ }^{24}$ 
Na Chamada Pública devem constar: a documentação necessária, as datas de recebimento e abertura dos envelopes com as propostas, local de julgamento, os produtos a serem adquiridos e suas especificações, as quantidades e valores a serem pagos, local e cronograma de entrega.

Em Alegre, uma comissão formada por lideranças de agricultores familiares e apoiadores se reúne antes com a Secretária de Educação e a nutricionista para negociar a variedade, a quantidade e os preços dos alimentos que serão adquiridos.

\section{Elaboração do projeto de venda}

O responsável pela elaboração do projeto de venda dos agricultores familiares deve ser o grupo formal (associações e cooperativas), grupo informal ou o fornecedor individual. O projeto deve estar em conformidade com a Chamada Pública e ser encaminhado à Secretaria de Educação, acompanhado da documentação exigida (conforme discriminado a seguir). No caso de grupo formal, só assina o representante legal, enquanto o projeto de grupo informal requer a assinatura de todos os agricultores participantes.

Antes de iniciar a elaboração dos projetos, em Alegre é feito o planejamento em conjunto da produção a ser ofertada para o PNAE municipal, que ocorre em numa reunião ampliada, contando com a presença de todos os agricultores familiares interessados e das entidades de apoio. ${ }^{g}$

\section{Recebimento e seleção dos projetos de venda}

A entrega do projeto de venda deve ser acompanhada da declaração de que os gêneros alimentícios a serem entregues são produzidos pelos agricultores familiares relacionados no projeto de venda. Além disso, é exigida a seguinte documentação de habilitação dos fornecedores:

- No caso dos grupos formais (associações e cooperativas): extrato da Declaração de Aptidão ao Pronaf (DAP jurídica), emitido nos últimos 30 dias, e CNPJ; Prova de regularidade com a Fazenda Federal, relativa à Seguridade Social e ao FGTS; e cópias do estatuto e ata de posse da atual diretoria da entidade registrada no órgão competente.

- No caso dos grupos informais e fornecedor individual: extrato da Declaração de Aptidão ao Pronaf (DAP física), emitido nos últimos 30 dias, e CPF de cada agricultor familiar participante.

g O projeto de extensão referido também vem auxiliando na elaboração dos projetos de venda. Inclusive, chegou a manter um bolsista-técnico para prestar essa ajuda (de novembro de 2013 a outubro de 2015), em dois dias semanais na sede do Sindicato, além de ter promovido uma capacitação de jovens, filhos de agricultores familiares, para elaboração desses projetos. 
A habilitação dos projetos de venda, que consiste na verificação dos projetos e da documentação, é feita em sessão pública registrada em ata. Inicialmente, deve-se observar que os produtos precisam atender à legislação sanitária e que o limite individual de venda do agricultor familiar é de $\mathrm{R} \$$ 20 mil por DAP/ano. Após a habilitação, a Secretaria de Educação faz a seleção dos projetos de venda, conforme os critérios estabelecidos na Resolução FNDE no 26/2013, ${ }^{22}$ devendo considerar a seguinte ordem de prioridade:

1. Fornecedores do município;

2. Assentamento de reforma agrária, comunidades tradicionais indígenas e comunidades quilombolas;

3. Alimentos certificados como orgânicos ou agroecológicos;

4. Grupos formais, priorizando aqueles com mais agricultores familiares;

5. Grupos informais;

6. Fornecedor individual;

7. Fornecedores de outros municípios.

No município de Alegre, na Chamada Pública de 2015, participaram nove (9) associações rurais (grupos formais) do município, sendo uma de assentamento de reforma agrária, e três (3) grupos informais, sendo um de município vizinho. Em 2013, foram seis (6) associações rurais do município, e em 2014, sete (7) associações rurais do município, um (1) grupo informal (com agricultores de Alegre e município vizinho) e dois (2) fornecedores individuais do município.

A avaliação dos alimentos a serem comercializados obedece a três critérios, como previsto na legislação:

1. Se atendem às especificações da chamada pública;

2. Se possuem certificação sanitária, quando houver essa exigência;

3. Se atendem ao teste de amostra, em que seja possível qualificar as suas características sensoriais. 


\section{Contrato de compra, entrega dos alimentos, termo de recebimento e pagamento dos agricultores}

Por meio do contrato ocorre a formalização do compromisso assumido entre a Secretaria de Educação e os agricultores familiares para atender à alimentação escolar, definindo direitos, obrigações e responsabilidades das partes, conforme os termos da Chamada Pública e do projeto a que se vincula.

O processo de entrega dos alimentos deve seguir o cronograma previsto no contrato. No ato da entrega, o "termo de recebimento" deve ser assinado pelo representante da Secretaria de Educação e pelo(s) fornecedor(es), atestando que os alimentos entregues estão de acordo com o previsto no contrato e dentro dos padrões de qualidade exigidos.

Em Alegre, assim que é emitida pela prefeitura a ordem de fornecimento, os produtores realizam a entrega diretamente no almoxarifado do PNAE e a logística de distribuição às escolas fica a cargo da prefeitura. No ato da entrega, o produtor também emite a nota fiscal (talão do produtor) devidamente preenchida, para, então, receber o pagamento.

\section{Caracterização da inserção da agricultura familiar no PNAE de Alegre}

O PNAE, além de buscar contribuir para a garantia da segurança alimentar e nutricional entre estudantes de escolas públicas, trabalha na construção de mercados locais como fator de incentivo ao desenvolvimento rural sustentável, uma vez que, após a descentralização do programa e a obrigatoriedade da compra de alimentos oriundos da agricultura familiar, tem colaborado para potencializar a produção diversificada e regional, como é o caso do município de Alegre-ES, o que será demonstrado a seguir.

Nesse município, desde o ano de 2010, é realizada a compra de alimentos da agricultura familiar para a alimentação escolar. As Chamadas Públicas do PNAE, que refletem o montante que a prefeitura se dispõe a adquirir (demanda) da agricultura familiar, tiveram aumentos significativos, com relação ao ano de 2013, conforme revela a figura 1. Entre os anos de 2013 e 2014 houve um aumento na demanda da ordem de 553\%, saindo de $\mathrm{R} \$ 105.690,63$ para o montante de $\mathrm{R} \$$ 584.474,72. Apesar de entre os anos de 2014 e 2015 esse montante ter se reduzido em 7,68\%, o valor ainda é 510,83\% superior ao do ano de 2013, chegando a R $\$ 539.904,80 .{ }^{25-27}$ 


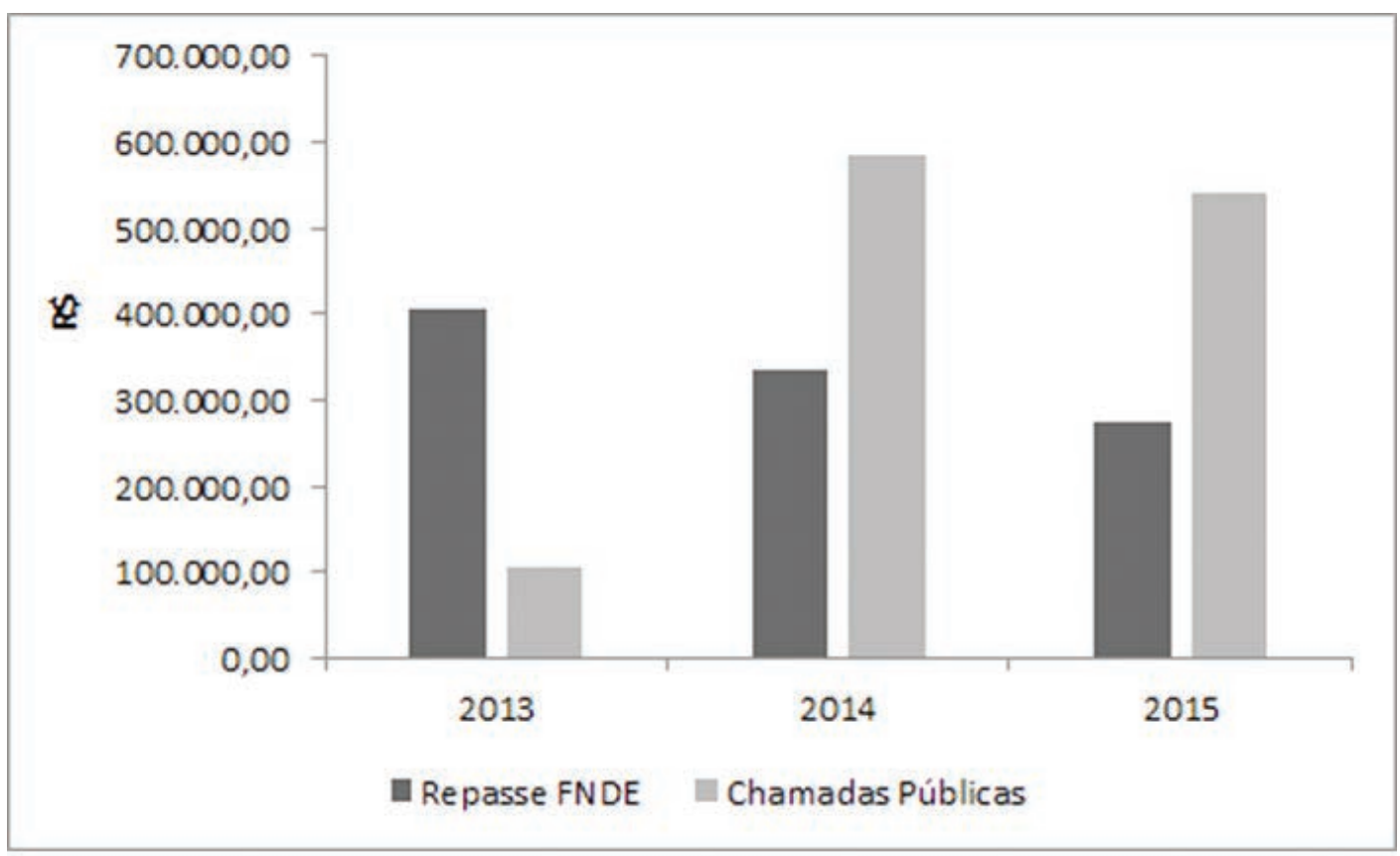

Figura 1. Valores de repasse do FNDE à Prefeitura Municipal de Alegre-ES e valores das Chamadas Públicas do PNAE, de 2013 a 2015.

Fonte: Dados da pesquisa.

Observa-se que a prefeitura, a partir de 2014, vem se propondo até mesmo a alocar recursos próprios, além dos repassados pelo FNDE, para efetuar esse tipo de compra de alimentos. Vale ressaltar que o valor de repasse do FNDE teve reduções no período em análise, como indicado na figura 1, passando de $\mathrm{R} \$ 405.820,00$, em 2013, para $\mathrm{R} \$ 333.840,00$, em 2014, e $\mathrm{R} \$ 275.340,00$, em $2015,{ }^{28}$ devido à redução no número de estudantes, principalmente.

Contudo, ao analisar minuciosamente os alimentos que constam dessas Chamadas Públicas, verifica-se a inclusão de um número significativo de alimentos não produzidos na região de Alegre, como pepino, couve-flor, repolho e farinha de mandioca. Isso acaba anulando, em parte, a iniciativa municipal de ampliar esses montantes, embora sejam pertinentes os esforços no sentido de diversificar o cardápio escolar a adquirir, ainda que seja oriundo de outros municípios.

Por isso, fica nítido o desafio de rever os critérios de formulação das Chamadas, procurando, no curto prazo, priorizar mais os alimentos já produzidos e, no médio/longo prazo, incentivar a diversificação para atender melhor à demanda das escolas. Esse incentivo vai depender de uma 
política agrícola específica da prefeitura, envolvendo, inclusive, parceria com órgãos como o Instituto Capixaba de Pesquisa, Assistência Técnica e Extensão Rural (INCAPER) e a Universidade Federal do Espírito Santo (UFES).

Teo \& Monteiro ${ }^{29}$ também analisaram essa questão, ao defender a importância do fornecimento de alimentos saudáveis para o PNAE, os quais deveriam ser, basicamente, alimentos in natura ou minimamente processados, provenientes da agricultura familiar. Para tanto, argumentam que os agricultores precisam de apoio dos órgãos de assistência no planejamento de sua produção de modo a atenderem melhor a essa demanda.

Motter \& Teo, ${ }^{30}$ ao estudar o processo de implementação do PNAE em dois municípios do Estado de Santa Catarina, observaram que houve adaptação dos cardápios para utilizar os alimentos disponibilizados pelos produtores familiares locais, mantendo os hábitos alimentares dos alunos e servindo, inclusive, de estratégia pedagógica para o ensino da importância da segurança alimentar e nutricional.

Analisando os projetos de venda apresentados pelos agricultores familiares e suas associaçóes, ou seja, a oferta de alimentos para participação nas Chamadas Públicas do PNAE de Alegre, conforme consta na figura 2, nota-se um aumento de 454,58\% no valor, de 2013 a 2015, visto que, em 2013, o montante era de $\mathrm{R} \$ 105.690,63$, passou para $\mathrm{R} \$ 396.618,86$, em 2014, e chegou a um valor total de $\mathrm{R} \$ 480.453,80$, em 2015 . Desse modo, ao confrontar com os dados da demanda pública municipal (Chamadas), tem-se a seguinte configuração: em 2013, demanda e oferta ficaram em equilíbrio; e em 2014 e 2015, a oferta foi menor que a demanda, nas proporções de 32,14\% e $11,01 \%$, respectivamente. 


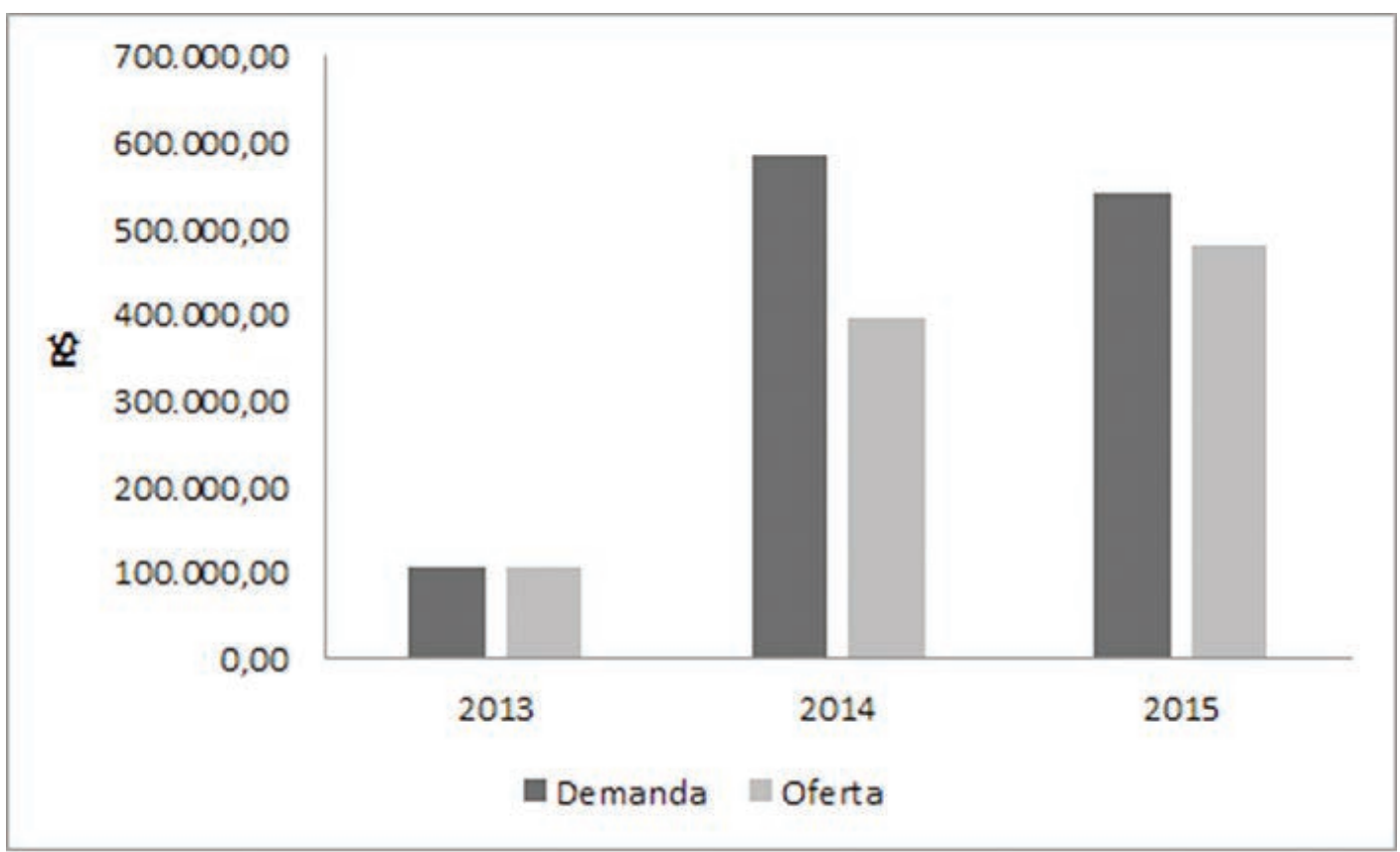

Figura 2. Demanda pública de alimentos e oferta da agricultura familiar nas Chamadas Públicas do PNAE de Alegre-ES, de 2013 a 2015.

Fonte: Dados da pesquisa.

Entretanto, ao considerar os dados preliminares apresentados pelo $\mathrm{FNDE}^{\mathrm{h}}$ como sendo aquilo que foi, realmente, efetivado pelo município nas compras da agricultura familiar, observa-se que apenas 15,52\% do repasse do FNDE foi usado, em 2013. Em compensação, no ano de 2014 utilizouse um valor maior que o total repassado pelo FNDE, equivalente a 116,68\% do mesmo. Em 2015, como o FNDE ainda não divulgou o quanto foi efetivado, menciona-se apenas o fato de que os projetos de venda (oferta) corresponderam a $89 \%$ do valor da Chamada Pública (demanda), de acordo com a figura 2. As ações coletivas, por parte das organizações dos agricultores familiares, forçando a gestão compartilhada do PNAE, foram decisivas para esse avanço.

h Dados disponíveis em: http://www.fnde.gov.br/programas/alimentacao-escolar/alimentacao-escolar-consultas/ dados-da-agricultura-familiar (acesso em: 23 nov. 2015). O FNDE informa que "os dados apresentados são preliminares, extraídos do Sistema de Gestão de Contas - SigPC - Contas Online do FNDE, em funcionamento a partir de 2011. Os registros do SigPC são realizados pelos gestores públicos municipais e estaduais responsáveis pela execução local PNAE, para fins de prestação de contas". Como as prestações de contas ainda estão sob análise, o FNDE ressalta que os dados apresentados são passíveis de alteração. 
Em comparação com municípios vizinhos, aplicando os mesmos dados preliminares do FNDE referidos, ${ }^{\text {h }}$ verifica-se que Guaçuí, por exemplo, utilizou 95,67\%, em 2013, e 59,43\%, em 2014, do repasse do FNDE para compras da agricultura familiar. Já o município de Jerônimo Monteiro, nos mesmos anos, fez uso de 0,0\% e 28,62\%, respectivamente, e Muniz Freire, de 39,11\% e 37,53\%, respectivamente. No ano de 2014, foi nítida a superioridade de Alegre, ao utilizar 116,68\% do repasse do FNDE nesse tipo de compra, enquanto em 2013 o destaque foi para o município de Guaçuí.

Cabe mencionar que, em 2015, a Secretaria Municipal de Educação de Alegre fez uma redução de $20 \%$ no total das compras previstas na Chamada Pública, caindo para $\mathrm{R} \$ 384.363,04$. Isso se deu por atraso na publicação da Chamada Pública e pela demora nos trâmites burocráticos da prefeitura. Sendo assim, as entregas, que deveriam ter se iniciado em fevereiro (início do ano letivo), só começaram no final de abril, dois meses após o início das aulas, o que levou à redução de $20 \%$ nas compras, já que o ano letivo é de dez meses. Esse fato aponta um grande desafio: a urgência de melhoria na eficiência administrativa do PNAE, o que levou à perda de dois meses de alimentação de melhor qualidade aos estudantes e de renda para os agricultores.

A população escolar atendida pelo programa no município passou por pequenas reduções sucessivas, totalizando, nos anos de 2013, 2014 e 2015, os seguintes números de estudantes, respectivamente: 2.522, 2.406 e 2.297. E o total de escolas municipais atendidas caiu de 40, em 2013, para 35, em 2014, e 30, em 2015. ${ }^{16}$ Essa redução foi devido, principalmente, ao fechamento de escolas rurais, o que acabou desfavorecendo os agricultores familiares, em contradição ao que prega o PNAE, afinal isso representa mais um fator de êxodo rural, como defendido por Peripolli \& Zoia. ${ }^{31}$

Quanto à diversidade de alimentos, houve um aumento da ordem de 54\%, passando de 22, em 2013, para 34 diferentes alimentos ofertados pelos agricultores, em 2015, como mostra a figura 3. Assim, a alimentação escolar ganha em quantidade e qualidade, com reflexo positivo na saúde das crianças e adolescentes. 


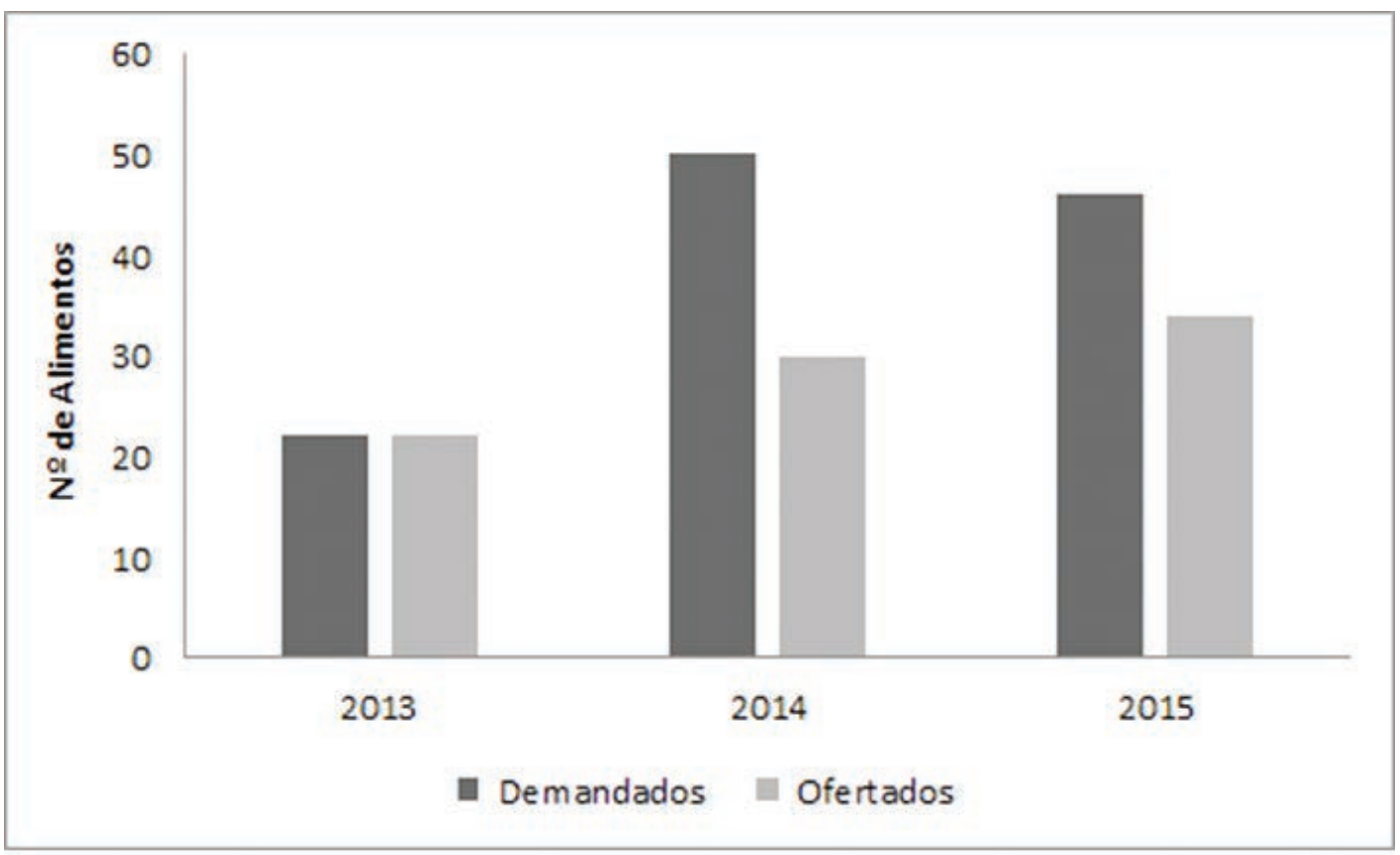

Figura 3. Variedade de alimentos demandados e ofertados para o PNAE de Alegre-ES, de 2013 a 2015.

Fonte: Dados da pesquisa.

Analisando o universo desses 34 alimentos ofertados pelos agricultores, em 2015, constatou-se que $32,4 \%$ deles correspondem ao grupo de hortaliças, $14,7 \%$ ao de frutas, 17,6\% ao de processados e $26,5 \%$ ao de minimamente processados. Os demais $(8,8 \%)$ são outros alimentos in natura. Nota-se que essa composição de oferta alimentar ficou compatível com o que defendem Teo \& Monteiro, ${ }^{29}$ ou seja, que os alimentos mais saudáveis para o PNAE deveriam ser, basicamente, alimentos in natura ou minimamente processados, os quais, em Alegre, corresponderam a 55,9\% e 26,5\%, respectivamente, totalizando $82,4 \%$ da oferta.

Amorim et al, ${ }^{32}$ ao enfocar as Chamadas Públicas referentes a 99 municípios do Estado de São Paulo, em 2013, constataram que os alimentos dos grupos de hortaliças e frutas foram os mais presentes, representando $50 \%$ e $31 \%$, respectivamente, do total dos alimentos a serem adquiridos. No caso de Alegre, considerando apenas o que consta na Chamada Pública de 2015 (demanda municipal), esses mesmos grupos representaram 40,4\% e 10,6\%, respectivamente, ficando bem abaixo da situação dos municípios paulistas na demanda de frutas (2/3 menor) para compor o cardápio escolar. 
Existe, ainda, um espaço não explorado pelos agricultores de Alegre, referente aos alimentos orgânicos, que são considerados mais saudáveis. Mesmo com o incentivo de $30 \%$ a mais no preço, previsto na legislação, não têm sido ofertados nas Chamadas Públicas. Somente uma agricultora do município vizinho (Guaçuí) chegou a oferecer morango orgânico.

Amorim et al ${ }^{32}$ constataram, no Estado de São Paulo, no ano de 2013, que somente em uma das 122 Chamadas Públicas analisadas (referentes a 99 municípios) havia sido incluído alimento orgânico, sendo apenas o arroz. Já no Estado de Santa Catarina, em 2010, Silva \& Sousa ${ }^{33}$ verificaram que somente nove dos 52 municípios analisados tinham adquirido algum alimento orgânico. E no Paraná, Melão ${ }^{12}$ constatou que 23\% das escolas atendidas pelo PNAE, em 2012, vinham adotando a alimentação orgânica.

Um interessante caso estrangeiro, analisado por Sonnino et al, ${ }^{6}$ foi referente à cidade de Roma, na Itália, que se destaca pela predominância de produtos orgânicos na alimentação escolar. As autoras relatam a importância dos incentivos governamentais nesse sentido, em especial a lei orçamentária italiana (no 488/1999), que determina o oferecimento de produtos agrícolas orgânicos em todos os serviços de refeições públicas, como meio de promoção da agricultura orgânica.

Outro indicador relevante do PNAE, em Alegre-ES, diz respeito à inserção de agricultores familiares do município nesse mercado. Nos últimos três anos houve um aumento muito significativo no número de participantes, ficando 2,8 vezes maior. Em 2013, 14 agricultores participaram; em 2014, foram 34; e em 2015, esse número chegou a 39 . Além deles, também participaram dois agricultores de um município vizinho, em 2015.

Em termos de grupos organizados participantes, evoluiu-se de seis (6) associações rurais (grupos formais) do município, em 2013, para nove (9) associações, em 2015, sendo uma de assentamento de reforma agrária, e três (3) grupos informais, sendo um de município vizinho. Acredita-se que, indiretamente, o PNAE esteja ajudando a fortalecer as organizações dos agricultores familiares, inclusive porque dá prioridade de aquisição de alimentos ofertados por grupos formais. Esse mesmo efeito também foi observado, por outros autores, no Estado de São Paulo ${ }^{34}$ e no município de Espera Feliz-MG. ${ }^{4}$

É de grande importância essa nova oportunidade de acesso ao mercado que o PNAE vem dando aos agricultores familiares, como alternativa de geração de trabalho e renda e incentivo à permanência no campo. Além disso, também contribui para dinamizar a economia local, já que eles também são consumidores, tanto de insumos e bens de produção como de produtos e bens de uso doméstico. Desse modo, aumenta-se a eficiência das políticas sociais do município na medida em que está aplicando seus recursos financeiros em prol do desenvolvimento agrícola local, incentivando a diversificação de culturas para garantir um cardápio variado e equilibrado nas escolas públicas, ao mesmo tempo que proporciona melhor distribuição da renda. 
Por parte da Prefeitura Municipal, constatou-se a falta de visão e planejamento das ações do PNAE, de modo intersetorial. Tal constatação se baseou na experiência extensionista do projeto (referido na seção anterior) coordenado pela Universidade Federal do Espírito Santo. Isso porque a questão da comercialização, para os agricultores familiares, envolve não somente a abertura de novos mercados, como o PNAE.

O atendimento da demanda diversificada de alimentos, que o mercado do PNAE levanta, requer assistência técnica e investimento para adequar a produção, a qual precisa contar com boa infraestrutura de transporte para chegar até o mercado. Além disso, as famílias rurais, para permanecerem no campo produzindo, precisam ter acesso à educação escolar no campo e à assistência médica, entre outras necessidades.

Portanto, trata-se de "desenvolvimento rural sustentável", cuja promoção vai depender de vontade política para que as secretarias municipais envolvidas (Educação, Agricultura, Meio Ambiente, Saúde e Obras) trabalhem, conjuntamente, em busca da solução dos referidos entraves. Um bom início seria, pelo menos, a integração entre as secretarias de Agricultura e Educação. Motter \& Teo $^{30}$ também relataram que ações conjuntas entre as mesmas possibilitam uma maior efetivação do PNAE, de acordo com a Lei de 2009.

Nesse sentido, é oportuno reforçar uma abordagem mais ampla do PNAE na perspectiva da "segurança alimentar e nutricional", que, segundo Leão \& Maluf:"35

[...] busca ampliar o acesso aos alimentos, ao mesmo tempo em que questiona o padrão inadequado de consumo alimentar, sugere formas mais equitativas, saudáveis e sustentáveis de produzir e comercializar os alimentos e requalifica as ações dirigidas para os grupos populacionais vulneráveis ou com requisitos alimentares específicos. Essas três linhas de ação convertem a busca da segurança alimentar e nutricional num parâmetro para as estratégias de desenvolvimento de um país, como também o são o desenvolvimento sustentável e a equidade social.

Finalmente, destaca-se a importância do processo de gestão compartilhada para o avanço do PNAE em Alegre, que envolve a Secretaria de Educação e as organizações sociopolíticas dos agricultores familiares, visando à construção participativa das Chamadas Públicas e dos projetos de venda de alimentos.

Vale ressaltar, nesse processo, o papel assumido pelo Sindicato dos Trabalhadores Rurais de Alegre, como legítimo representante dos agricultores familiares, passando a ser protagonista nas questões relativas ao PNAE, que abrangem: a negociação com a Secretaria de Educação de pontos-chave, como a variedade e os preços dos alimentos; o planejamento em conjunto da produção a ser ofertada, com as associações; e a elaboração autônoma dos seus projetos de venda de alimentos. Também se observou que a questão da inserção dos agricultores no PNAE passou 
a fazer parte, muitas vezes, da pauta das reuniões mensais da Rede da Agricultura Familiar de Alegre, que são promovidas pelo Sindicato, contando com a participação de representantes de várias associações rurais.

\section{Conclusões}

No município de Alegre-ES, no período de 2013 a 2015, o PNAE cresceu com relação aos valores das Chamadas Públicas e dos projetos de venda apresentados pelos agricultores familiares. Verificou-se que o percentual mínimo de compra obrigatória não foi cumprido no ano de 2013, ficando em 15,52\%, mas, por outro lado, a prefeitura aplicou em aquisições da agricultura familiar, no ano de 2014, um valor maior que o total repassado pelo FNDE, equivalente a 116,68\% do mesmo. E em 2015, sabe-se apenas que os projetos de venda dos agricultores corresponderam a $89 \%$ do valor da Chamada Pública, pois ainda não foi divulgado o quanto se adquiriu efetivamente. Houve um aumento de 2,8 vezes no número de agricultores familiares inseridos nesse mercado institucional, chegando a 39 agricultores, e foi ampliada em $54 \%$ a diversidade dos alimentos ofertados, obtendo-se 34 diferentes alimentos.

Destaca-se a importância do processo de gestão compartilhada para o avanço do PNAE em Alegre, possibilitando realizar a construção participativa das Chamadas Públicas e dos projetos de venda de alimentos. As ações coletivas, por parte das organizações dos agricultores familiares, foram decisivas para esse avanço.

Dessa forma, em Alegre, o PNAE vem demonstrando o seu potencial de interligar a agricultura familiar local à alimentação escolar, visando proporcionar segurança alimentar e nutricional às crianças e adolescentes das escolas públicas e, ao mesmo tempo, contribuir com o desenvolvimento das áreas rurais do município de modo sustentável.

Contudo, um dos grandes desafios a serem trabalhados é fazer com que o poder público municipal perceba a dimensão sistêmica do PNAE, ao relacionar os temas agricultura familiar, alimentação, desempenho escolar e desenvolvimento local sustentável. Isso implicaria definir e implementar ações de caráter intersetorial, envolvendo as secretarias de Educação, Agricultura, Meio Ambiente, Saúde e Obras.

\section{Colaboradores}

Rodrigues R participou de todas as etapas; Siqueira HM participou da concepção do estudo, análise dos dados, revisão de literatura e redação do artigo; Biancardi CCS participou da concepção do estudo, coleta e análise dos dados e adequação às normas da revista; Andrade MAN participou da 
análise dos dados e redação do artigo; Valente LM e Paula LB participaram da coleta dos dados, revisão de literatura e adequação às normas da revista.

Conflito de Interesses: Os autores declaram não haver conflito de interesses.

\section{Referências}

1. Fundo Nacional de Desenvolvimento da Educação. Programa Nacional de Alimentação Escolar. Histórico [Internet]. Brasília: FNDE; 2012. [acesso em: 07 mar 2016]. Disponível em: http://www. fnde.gov.br/programas/alimentacao-escolar/alimentacao-escolar-historico

2. Brasil. Lei no 11.947 , de 16 de junho de 2009. Dispõe sobre o atendimento da alimentação escolar e do Programa Dinheiro Direto na Escola aos alunos da educação básica. Diário Oficial da União 17 jun. 2009.

3. Triches RM, Froehlich E, Schneider S. Relações de produção e consumo: a aquisição de produtos da agricultura familiar para o Programa de Alimentação Escolar no município de Dois Irmãos (RS). In: Schneider S, Gazolla M, organizadores. Os atores do desenvolvimento rural: perspectivas teóricas e práticas sociais. Porto Alegre: UFRGS; 2011. p. 253-268.

4. Cunha WA. Efeitos dos programas governamentais de aquisição de alimentos para a agricultura familiar no contexto local [dissertação]. [Viçosa-MG]: Universidade Federal de Viçosa; 2015.

5. Belik W, Domene SMA. Experiências de programas combinados de alimentação escolar e desenvolvimento local em São Paulo - Brasil. Revista Agroalimentaria 2012; 18(34):57-72.

6. Sonnino R, Spayde J, Ashe L. Políticas públicas e a construção de mercados: percepções a partir de iniciativas de merenda escolar. In: Marques FC, Conterato MA, Schneider S, organizadores. Construção de mercados e agricultura familiar: desafios para o desenvolvimento rural. Porto Alegre: UFRGS; 2016. p. 311-329.

7. Wilkinson J. Mercados, redes e valores: o novo mundo da agricultura familiar. Porto Alegre: UFRGS; 2008.

8. Saraiva EB, Silva APF, Sousa AA, Cerqueira GF, Chagas CMS, Toral N. Panorama da compra de alimentos da agricultura familiar para o Programa Nacional de Alimentação Escolar. Ciênc Saúde Coletiva 2013; 18(4):927-936.

9. Alves LS. O Programa Nacional de Alimentação Escolar e a recriação do camponês. Anais do Congresso Brasileiro de Geógrafos; 10-16 ago. 2014; Vitória-ES. Vitória: AGB; 2014. 12 p. [acesso em: 03 mar. 2016]. Disponível em: http://www.cbg2014.agb.org.br/resources/anais/1/1404146164_ ARQUIVO_completo_cbg.pdf

10. Aoki P, Fontes L, Amorim B, Salagado JS. A organização da agricultura familiar e a política governamental do Programa Nacional de Alimentação Escolar: o caso de Pedro Canário, Espírito Santo. Cadernos de Agroecologia 2013; 8(2):1-5.

11. França CG, Del Grossi ME, Marques VPMA. O censo agropecuário 2006 e a agricultura familiar no Brasil. Brasília: Ministério do Desenvolvimento Agrário, Núcleo de Estudos Agrários e Desenvolvimento Rural; 2009. 95 p. 
12. Melão IB. Produtos sustentáveis na alimentação escolar: o PNAE no Paraná. Caderno IPARDES 2012; 2(2):87-105.

13. Turpin ME. A alimentação escolar como fator de desenvolvimento local por meio do apoio aos agricultores familiares. Segurança Alimentar e Nutricional 2009; 16(2):20-42.

14. Siqueira HM, Carneiro JJ, Falce BO, Fernandes MA, Biancardi CCS, Rodrigues R. Gestão compartilhada de mercados para agricultura familiar. Cadernos de Agroecologia 2015; 10(1):1-5.

15. Instituto Brasileiro de Geografia e Estatística. Espírito Santo, Alegre [Internet]. [acesso em: 07 mar. 2016]. Disponível em: http://www.cidades.ibge.gov.br/xtras/perfil.php?lang=\&codmun=320020\& search=espirito-santo $\mid$ alegre.

16. Fundo Nacional de Desenvolvimento da Educação. Alunado por ação do Programa Nacional de Alimentação Escolar [Internet]. [acesso em: 07 mar. 2016]. Disponível em: https://www.fnde.gov. br/pnaeweb/publico/relatorioDelegacaoEstadual.do.

17. Panzutti NPM. Mercado como construção social da realidade. Informações Econômicas 2011; 41(7):60-72.

18. Schneider S. Mercados e agricultura familiar. In: Marques FC, Conterato MA, Schneider S, organizadores. Construção de mercados e agricultura familiar: desafios para o desenvolvimento rural. Porto Alegre: UFRGS; 2016. p. 93-140.

19. Malina LL. Chamada pública: instrumento legal de compras da agricultura familiar para a alimentação escolar. In: Corá MAJ, Belik W, organizadores. Projeto Nutre, SP: análise da inclusão da agricultura familiar na alimentação escolar no estado de São Paulo. São Paulo: Instituto Via Pública; 2012. p.1328. [acesso em: 07 mar. 2016]. Disponível em: https://www.google.com.br/webhp?sourceid=chromeinstant\&ion $=1 \&$ espv $=2 \&$ ie $=\mathrm{UTF}-8 \# \mathrm{q}=$ Projeto + Nutre $+\mathrm{SP} \% 3 \mathrm{~A}+\mathrm{an} \% \mathrm{C} 3 \% \mathrm{~A} 1$ lise $+\mathrm{da}+\mathrm{inclus} \% \mathrm{C} 3$ $\% \mathrm{~A} 3 \mathrm{o}+\mathrm{da}+$ agricultura + familiar + natalimenta $\% \mathrm{C} 3 \% \mathrm{~A} 7 \% \mathrm{C} 3 \% \mathrm{~A} 3 \mathrm{o}+$ escolar + no + estado $+\mathrm{de}+\mathrm{S} \%$ C3\%A3o+Paulo.

20. Aroucha EPTL. Agricultura familiar na alimentação escolar: estudo de oportunidades e de desafios [dissertação]. Paulo Afonso-BA: Universidade do Estado da Bahia; 2012.

21. Belik W. Os limites para a expansão dos mercados locais. In: Marques FC, Conterato MA, Schneider $\mathrm{S}$, organizadores. Construção de mercados e agricultura familiar: desafios para o desenvolvimento rural. Porto Alegre: UFRGS; 2016. p. 183-205.

22. Fundo Nacional de Desenvolvimento da Educação - FNDE. Resolução no 26, de 17 de junho de 2013. Dispõe sobre o atendimento da alimentação escolar aos alunos da educação básica no âmbito do Programa Nacional de Alimentação Escolar. Diário Oficial da União 18 jun. 2013.

23. Chaves LG, Santana TCM, Gabriel CG, Vasconcelos FAG. Reflexões sobre o papel do nutricionista no Programa Nacional da Alimentação Escolar no Brasil. Ciênc Saúde Coletiva 2013; 18(4):917-926.

24. Fundo Nacional de Desenvolvimento da Educação. Programa Nacional de Alimentação Escolar agricultura familiar [Internet]. [acesso em: 02 dez. 2016]. Disponível em: http://www.fnde.gov.br/ programas/alimentacao-escolar/alimentacao-escolar-material-de-divulgacao/alimentacao-manuais 
25. Prefeitura Municipal de Alegre. Relatório de Chamada Pública no 001/2013 [Internet]. [acesso em: 29 set. 2015]. Disponível em: http://alegre.es.gov.br/site/index.php/diario-oficial-municipal/licitacoes/ resultado/162-resultado-do-chamamento-publico-n-001-2013

26. Prefeitura Municipal Alegre. Relatório de Chamada Pública -2014. [acesso em: 29 set. 2015]. Disponível em: http://alegre.es.gov.br/site/index.php/diario-oficial-municipal/licitacoes/676-pregao-presencialrp-004-14-aquisicao-de-materiais-generos-alimenticios

27. Prefeitura Municipal Alegre. Relatório de Chamada Pública - 2015. [acesso em: 29 set. 2015]. Disponível em: http://alegre.es.gov.br/site/images/diario- oficial/licitacoes/relatorios_licitacoes/2015/ Relatorio\%20CP\%20001-15\%20-\%20Agricultura\%20Familiar.pdf

28. Fundo Nacional de Desenvolvimento da Educação. Alimentação escolar, repasses financeiros [Internet]. [acesso em: 07 mar. 2016]. Disponível em: http://www.fnde.gov.br/programas/alimentacaoescolar/alimentacao-escolar-consultas/repasses-financeiros

29. Teo CRPA, Monteiro CA. Marco legal do Programa Nacional de Alimentação Escolar: uma releitura para alinhar propósitos e práticas na aquisição de alimentos. Rev Nutr. 2012; 25(5):657-668.

30. Motter AF, Teo CRPA. Agricultura familiar: desafios e dificuldades na aproximação com o Programa Nacional de Alimentação Escolar. Anais do Congresso Virtual Brasileiro de Educação, Gestão e Promoção da Saúde; 2012; São Paulo. São Paulo: Convibra Saúde; 2012. [acesso em: 03 nov. 2016]. Disponível em: http://www.convibra.com.br/upload/paper/2012/69/2012_69_4079.pdf

31. Peripolli OJ, Zoia A. O fechamento das escolas do campo: o anúncio do fim das comunidades rurais/ camponesas. Educação, Cultura e Sociedade 2011; 1(2):188-202.

32. Amorim ALB, Rosso VV, Bandoni DH. Acquisition of family farm foods for school meals: analysis of public procurements within rural family farming published by the cities of São Paulo state. Rev Nutr. 2016; 29(2):297-306.

33. Silva APF, Sousa AA. Alimentos orgânicos da agricultura familiar no Programa Nacional de alimentação Escolar do Estado de Santa Catarina, Brasil. Rev Nutr. 2013; 26(6):701-714.

34. Souza LBB. Organizações da agricultura familiar no Estado de São Paulo e sua experiência de fornecimento para o PNAE. In: Corá MAJ, Belik W, organizadores. Projeto Nutre SP - análise da inclusão da agricultura familiar na alimentação escolar no estado de São Paulo. São Paulo: Instituto Via Pública; 2012. p. 29-45.

35. Leão MM, Maluf RS. A construção social de um sistema público de segurança alimentar e nutricional: a experiência brasileira. Brasília: ABRANDH; 2012.

Recebido: 19/12/2016

Aceito: 29/1/2017 